\title{
ALGUNS ASPECTOS DA PRESENÇA DE EDGAR ALLAN POE NO BRASIL
}

\section{Denise Bottmann}

Este artigo trata da presença de Edgar Allan Poe no Brasil, desde o começo do século XX até o presente, abordando três aspectos específicos: a primeira edição brasileira de contos de Poe, as traduções de The Black Cat e as várias antologias enfeixadas sob o título de Histórias extraordinárias.

I.

A primeira publicação de contos de Poe no Brasil, até onde tenho notícia, é a coletânea chamada Novellas extraordinarias, publicada por H. Garnier Livreiro-Editor. O volume não traz a data de publicação, mas o cadastro do exemplar depositado no acervo da Biblioteca Nacional de Portugal registra o ano de 1903 (Poe, c.1903). ${ }^{1}$

O livro traz em sua página de rosto, logo abaixo do título, a especificação “(Traducção Brasileira)”, sem citar, porém, o nome do tradutor. A coletânea traz dezoito contos de Poe, além do texto “O corvo (Gênese de um poema)”, a versão em prosa que Charles Baudelaire fez de The Raven. Esse elemento, por si só, já bastaria para sugerir que se trata de uma tradução feita a partir do francês.

Os escritos presentes nessa coletânea são: “O rei peste”; “O corvo (Gênese de um poema)”; "Pequena discussão com uma múmia”; “O homem das multidões”; “O sistema do doutor Breu e do professor Pena”; "Colóquio entre Monos e Uma”; “Colóquio entre Eiros e Charmion”; "Poder da palavra”; “A carta roubada”; "Duplo assassínio na rua Morgue”; “O escaravelho de ouro”; “O poço e o pêndulo”; "Hopfrog”; “O demônio da perversidade”; “O gato preto”; "William Wilson”; "Silêncio”; “Sombra”; "Berenice”.

Em 1941, a editora paulista O Livro de Bolso publica um pequeno volume também chamado Novelas extraordinárias (Poe, 1941). Na página de rosto, logo abaixo

\footnotetext{
${ }^{1}$ A edição certamente não é anterior ao ano de 1901, visto constar a seguinte nota de rodapé a "O corvo (a gênese de um poema)": "O illistre [sic] sr. Machado de Assis tem uma bellisisima traduç̧ão deste poema (V. Poesias completas, H. Garnier)”, op. cit., p. 17. Como se sabe, a primeira edição das Poesias Completas de Machado saiu por H. Garnier em 1901.
} 
do título da obra, vem a especificação “Tradução portuguesa, revista por Faria e Sousa”. O volume traz o mesmo "O corvo (A gênese de um poema)", complementado pelo artigo "Método de composição" (também seguindo a tradução baudelaireana de Philosophy of composition) e uma transcrição de $O$ corvo na tradução de Machado de Assis, porém incompleta, à qual faltam as três estrofes finais. Seguem-se nove contos, a saber: "O escaravelho de ouro"; "O homem das multidões”; “O poço e o pêndulo"; “Hop-Frog”; “O demônio da perversidade”; "William Wilson”; "Silêncio”; "Sombra”; "Berenice".

Em 1943, a editora Cruzeiro do Sul publica a mesma coletânea lançada pela editora O Livro de Bolso, desta feita apresentando Faria e Souza diretamente como tradutor da obra (Poe, 1943).

Em 1945, o Clube do Livro reedita a mesma coletânea acrescida de um décimo conto, “O sistema do dr. Breu e do prof. Pena”, além da versão baudelaireana de $O$ corvo, do "Método de composição" e da tradução de Machado de Assis, agora completa. Não há qualquer menção ao tradutor ou à tradução utilizada (Poe, 1945).

Em 1972, a editora Ordibra, em convênio com o Instituto Nacional do Livro/MEC, publica uma coletânea com o nome de Histórias extraordinárias, com a mesma versão em prosa de $O$ corvo, o texto “Método de composição” e a tradução do poema feita por Machado de Assis. Inclui dezesseis contos, sendo os mesmos da edição de 1903, excluídos os dois Colóquios. Como tradutor da obra consta o nome de João Teixeira de Paula (Poe, 1972). O verso da página de rosto especifica: "Direitos de tradução da Editora Clube do Livro Ltda. especialmente cedidos à Ordibra Organização Editorial Brasileira Ltda.”

Alinhavei essas cinco edições, desde c. 1903 até 1972, por uma razão simples: mediante a simples comparação entre elas, constata-se que se trata exatamente da mesma obra de tradução, quer apareça como brasileira anônima, portuguesa anônima revisada por Faria e Sousa, ou brasileira atribuída a Faria e Souza ou a João Teixeira de Paula.

No caso da edição da Ordibra em convênio com o INL, entendo que se trata de uma franca cópia lastimavelmente subvencionada com verbas públicas. Do ponto de vista histórico-cultural, porém, o que me chama mais a atenção são as duas referências: “(Traducção brasileira)” na edição de H. Garnier e “Tradução portuguesa revista por Faria e Sousa” na edição de O Livro de Bolso. 
Por que O Livro de Bolso diria ser portuguesa uma tradução na verdade brasileira? Talvez pela questão de exclusividade dos direitos autorais? Embora a Garnier já tivesse mudado de mãos algumas vezes desde 1903 e, aliás, encerrara suas atividades na década de 1930, teria O Livro de Bolso decidido arriscar a lusitanização da tradução brasileira para fugir à obrigação de licenciá-la para publicação? Ou teria talvez Hyppolite Garnier estampado os dizeres “Traducção Brasileira” numa obra de tradução portuguesa, apenas para atender às pressões crescentes da lei de direitos autorais de 1898? Difícil saber (Hallewell, 1985: 170-195).

Por outro lado, seria até bastante simples saber, recorrendo a um meio ao qual ainda não tive acesso. Creio que seria muito interessante comparar a coletânea Novellas extraordinarias de H. Garnier, c. 1903, e as pioneiras coletâneas traduzidas por Mécia Mousinho de Albuquerque, pela interposição do francês, para a lisboeta Companhia Nacional.

A primeira delas, publicada em 1889, traz nove contos: "O escaravelho de ouro"; "O poço e o pêndulo”; "Hop Frog”; “O demônio da perversidade”; "O gato preto”; “William Wilson”; “Silêncio”; “Sombra”; “Berenice” (Poe, 1889).

A outra, publicada em 1890 pela mesma editora, traz: “O rei peste”; “A gênese de um poema"; "Pequena discussão com uma múmia”; “O homem das chusmas”; “O sistema do dr. Breu e do professor Pena”; “Colóquio entre Monon e Uma”; “Colóquio entre Eiros e Charmion”; “O poder da palavra” (Poe, 1890).

É interessante notar que não só a seleção das Novellas extraordinárias pela H. Garnier é praticamente idêntica, como a própria ordem dos contos é a mesma, começando pelo conteúdo da edição portuguesa de 1890 e depois passando para a de 1889. Apenas dois contos da edição brasileira — “A carta roubada” e "Duplo assassínio na rua Morgue” - não fazem parte das antologias portuguesas, e curiosamente se encontram de entremeio entre os dois blocos de contos do índice de H. Garnier que reproduzem os contos da Companhia Nacional.

Não seria difícil tirar a dúvida a limpo. Bastaria compulsar as edições de 1889 e 1890 no acervo da Biblioteca Nacional de Portugal, todavia indisponíveis para consulta!

Isso é o que tenho a dizer sobre a primeira antologia de contos de Edgar Allan Poe publicada no Brasil. Devido à ausência dos créditos de tradução e a posteriores menções a uma "tradução portuguesa” idêntica a ela, não posso afirmar se é simples cópia ou se é de fato uma "traducção brasileira” de direito próprio. Seja como for, 
setenta anos depois essa mesma tradução continuava a ser copiada sem pejo, no caso da edição da Ordibra.

II.

Desta primeira antologia Novellas extraordinarias, gostaria de destacar o conto O gato preto. As razões que me levaram a destacá-lo são um tanto circunstanciais, mas, após o levantamento de suas traduções no país, vi confirmada uma intuição inicial: trata-se do conto de Poe, se não o mais traduzido, pelo menos entre os mais traduzidos no Brasil.

Edgar Allan Poe escreveu The Black Cat no final de 1842 ou começo de 1843. O conto foi publicado no Saturday Evening Post, na edição de 19 de agosto de 1843. Em 1845, The Black Cat foi incluído na coletânea Tales, organizada por Poe e publicada por Wiley \& Putnam, Nova York. ${ }^{2}$

Como expus acima, não tenho certeza se sua primeira tradução dita brasileira é de fato brasileira. ${ }^{3}$ Se for, podemos situar a data de nosso primeiro gato preto por volta do ano de 1903. Depois disso, temos uma nova tradução em 1944, esta com certeza brasileira, e desde então $O$ gato preto tem conhecido várias outras traduções e adaptações ao longo das décadas.

Arrolo abaixo os nomes dos tradutores e adaptadores, as editoras e o ano da primeira edição que consegui localizar. Entre parênteses constam outras editoras que publicaram a mesma tradução, com licenciamento. Entre colchetes consta a língua de interposição e/ou eventual cópia e adulteração, quando for o caso.

- Anônimo, ed. H. Garnier, 1903 [pelo francês, sem indicação; dúvida sobre sua autenticidade];

- Oscar Mendes e Milton Amado, ed. Globo, 1944 (José Aguilar, Nova Aguilar, Nova Fronteira);

- Aurélio Lacerda, ed. Pinguim, 1947;

- Frederico dos Reis Coutinho, ed. Vecchi, 1954;

- Anônimo, ed. Tecnoprint, 1954;

- José Paulo Paes, ed. Cultrix, 1958 (Companhia das Letras);

${ }^{2}$ Para referências sobre a vida e a obra de Poe, ver The Edgar Allan Poe Society of Baltimore, http://www.eapoe.org.

${ }^{3}$ De qualquer forma, a primeira tradução de The black cat para a última flor do Lácio é, sem margem de dúvidas, a de Mécia Mousinho de Albuquerque, feita a partir do francês. 
- Brenno Silveira, ed. Civilização Brasileira, 1959 (Círculo do Livro, Abril Cultural, Edibolso, Nova Cultural);

- Aldo della Nina, ed. Saraiva, 1961;

- João Teixeira de Paula, Ordibra/INL, 1972 [pelo francês, sem indicação; cópia da edição de 1903, provavelmente via Clube do Livro];

- Clarice Lispector, ed. Tecnoprint e Ediouro, c. 1975;

- Renato Guimarães, ed. Civilização Brasileira, 1978;

- José Rubens Siqueira, ed. Ática, 1993;

- Annunziata Capasso de Filippis, ed. Newton Compton, 1995 [pelo italiano, sem indicação];

- Geraldo Galvão Ferraz, ed. Ática, 1998;

- Pietro Nassetti, ed. Martin Claret, 1999 [cópia adulterada de Brenno Silveira];

- Celso Mauro Paciornik, ed. Iluminuras, 2001;

- William Lagos, ed. L\&PM, 2002;

- Bernardo Carvalho, ed. Cosac Naify, 2004;

- Cláudia Ortiz, ed. Escala/Larousse, 2005 [pelo francês, com indicação];

- Rodrigo Espinosa Cabral, ed. Rideel, 2005;

- Henry Dualib, ed. Germape, 2005 [provável cópia de Tomé Santos Jr.];

- Antonio Carlos Vilela, ed. Melhoramentos, 2006 [pelo espanhol, com indicação];

- Celina Portocarrero, Ediouro, 2007;

- Ricardo Gouveia, ed. Scipione, 2007;

- Anônimo, ed. Cedic, 2008 [cópia de Tomé Santos Jr.];

- Guilherme Braga, ed. Hedra, 2008.

Menciono ainda as traduções portuguesas de Januário Leite e de Luísa Feijó, que foram publicadas no Brasil respectivamente pela ed. Annuario do Brasil, 1926, ${ }^{4}$ e pela ed. América do Sul, 1988.

As traduções, em sua grande maioria, trazem o título O gato preto. As exceções são O mistério do gato preto (tradução anônima, Tecnoprint, 1954), O gato negro (Luísa Feijó; José Rubens Siqueira) e Gato negro (Rodrigo Espinosa Cabral).

\footnotetext{
${ }^{4}$ Aliás, até onde sei, essa tradução de $O$ gato preto, feita em 1922 pelo poeta e escritor caboverdiano Januário Leite, radicado em Portugal, e publicada entre nós em 1926 na coletânea Contos de imaginação e mysterio, de Edgard Poe [sic], é a primeira em língua portuguesa vertida diretamente do original inglês.
} 
Concluindo esta parte, temos 28 edições de The Black Cat no Brasil, em princípio diferentes, sendo duas portuguesas e 26 brasileiras (com a dúvida pendente no caso da edição de 1903). Dessas 26 brasileiras, quatro são casos de simples cópia e/ou plágio. Assim teríamos 22 traduções brasileiras legítimas, com um lapso temporal de mais de trinta anos entre a primeira delas (se o for) e a subsequente (1944). As demais 21 traduções se distribuem entre 1944 e 2008, mostrando forte concentração a partir de 1993 (doze delas) e sobretudo após 2001 (nove delas). Em outros termos, quase 41\% do total de edições ao longo de 105 anos concentra-se num curtíssimo prazo de apenas oito anos.

III.

The Black Cat, nas traduções acima arroladas, geralmente encontra-se publicado em antologias. Raros são os casos de edições exclusivamente dedicadas apenas a este conto.

A distribuição de $O$ gato preto é a seguinte:

1. Sozinho:

- O gato preto, trad. Bernardo Carvalho, Cosac Naify, 2004;

- O gato preto, trad. Antonio Carlos Vilela, Melhoramentos, 2006.

2. Miscelâneas de autores:

- Os mais extraordinários contos de suspense, trad. Renato Guimarães, Civilização Brasileira, 1978;

- Clássicos do conto norte-americano, trad. Celso M. Paciornik, Iluminuras, 2001;

- Os melhores contos de medo, horror e morte, trad. Oscar Mendes e Milton Amado, Nova Fronteira, 2005;

- Os melhores contos de cães e gatos, trad. Celina Portocarrero, Ediouro, 2007.

3. Coletâneas de Poe: ${ }^{5}$

- Os já referidos Contos de imaginação e mysterio, trad. Januário Leite, Annuario do Brasil, 1926;

\footnotetext{
${ }^{5}$ Em março de 2010 foi lançada uma coletânea com o título de Antologia de contos extraordinários, pela Editora BestSeller, não incluída neste levantamento. Em todo caso, é praticamente uma reedição das Histórias extraordinárias publicadas pela Civilização Brasileira em 1970, na tradução de Brenno Silveira.
} 
- Um homônimo Contos de imaginação e mistério, trad. Aurélio Lacerda, Pinguim, 1947 ;

- O mistério do gato preto, tradução anônima, Tecnoprint, 1954;

- O fantasma da rua Morgue, trad. Frederico dos Reis Coutinho, Vecchi, 1954;

- Antologia de contos de Edgar Allan Poe, trad. Brenno Silveira, Civilização Brasileira, 1959;

- Contos de terror, de mistério e de morte, trad. Oscar Mendes e Milton Amado, José Aguilar, 1975; Nova Fronteira, 1981;

- Os crimes da rua Morgue e outras histórias, trad. Aldo della Nina, Saraiva, 1961; reed. como Assassinatos na rua Morgue e outras histórias em 2006;

- O gato preto e outras histórias de Allan Poe, trad. Clarice Lispector, Ediouro, c. 1975;

- Contos escolhidos, trad. Oscar Mendes e Milton Amado, Globo, 1985;

- O escaravelho de ouro e outras histórias, trad. José Rubens Siqueira, Ática, 1993;

- Histórias de crime e mistério, trad. Geraldo Galvão Ferraz, Ática, 1998;

- Os assassinatos da rua Morgue e outras histórias, trad. William Lagos, L\&PM, 2002;

- O escaravelho de ouro e Gato negro, trad. Rodrigo Espinosa Cabral, Rideel, 2005;

- O gato preto e outras histórias, trad. Ricardo Gouveia, Scipione, 2007;

- O gato preto e outros contos, trad. Guilherme Braga, Hedra, 2008.

\section{Histórias extraordinárias:}

Aqui surge um dado que considero muito interessante: a presença do conto $O$ gato preto em diversas antologias com o mesmo nome.

- Histórias extraordinárias, seleção e tradução de José Paulo Paes, com dezoito contos, Cultrix, 1958; Companhia das Letras, 2008;

- Histórias extraordinárias, seleção e tradução de Brenno Silveira, com treze contos, Civilização Brasileira, 1970;

- Histórias extraordinárias, tradução de João Teixeira de Paula, com dezesseis contos, Ordibra/INL, 1972 (no já referido plágio da edição de 1903);

- Histórias extraordinárias, tradução de Brenno Silveira e outros, com dezessete contos, Civilização Brasileira, 1973, licença para o Círculo do Livro; 
- Histórias extraordinárias de Allan Poe, tradução e adaptação de Clarice Lispector, com dezoito contos, Ediouro (seleta de c. 1975, com esse título desde c. 1985); reed. com o nome Histórias extraordinárias a partir de 2005;

- Histórias extraordinárias, tradução de Brenno Silveira e outros, com onze contos, Edibolso, 1975 ( $3^{\text {a }}$. ed.);

- Histórias extraordinárias, tradução de Brenno Silveira e outros, com dezesseis contos, Civilização Brasileira (1978 em diante) em licença para Abril Cultural, Círculo do Livro, Nova Cultural;

- Histórias extraordinárias, seleção de Carmen Vera Cirne Lima, tradução de Oscar Mendes e Milton Amado, Globo, 1987;

- Histórias extraordinárias, pretensa tradução de Pietro Nassetti, com sete contos, Martin Claret, 1999;

- Histórias extraordinárias, tradução de Cláudia Ortiz, com sete contos, Larousse, 2005;

- Histórias extraordinárias, tradução portuguesa de Luísa Feijó e Teixeira de Aguilar, com seis contos, ed. brasileira América do Sul, 1988.

Salta à vista a surpreendente proliferação de antologias com o mesmo título, embora variem no conteúdo e na quantidade de contos reunidos. As onze coletâneas de Histórias extraordinárias acima arroladas incluem $O$ gato preto. Além delas, existem mais três com o mesmo título, mas sem o referido conto:

- Histórias extraordinárias, tradução de Pedro Ramires, com oito contos, Cedibra, 1972 ;

- http://2.bp.blogspot.com/zzVPImTviU9s/SjPYqUw7pFI/AAAAAAAACcY/RoQFZ 7vqqEM/s1600-h/poe,+otto+pierre+he.jpgHistórias extraordinárias, tradutor anônimo, com oito contos, Otto Pierre, 1979;

- Histórias extraordinárias, tradução de José Maria Machado, com dez contos, Clube do Livro, $1988{ }^{6}$

\footnotetext{
${ }^{6}$ Ver no Anexo a relação completa dos contos incluídos nas várias antologias de nome Histórias extraordinárias.
} 
A título de curiosidade, fiz um levantamento cruzando conteúdo e frequência dos contos enfeixados sob o título Histórias extraordinárias, incluindo as três edições que não trazem o conto $O$ gato preto. Os dados abaixo se referem a treze coletâneas (omiti a seleta de Cirne Lima, Globo, 1987, pois não tive acesso a seu conteúdo).

O conteúdo dessas treze antologias varia de seis a dezoito contos. São, ao todo, 37 contos diferentes com um total de 156 ocorrências, ou seja, uma média geral de doze contos por coletânea. A coletânea mais abrangente traz dezoito contos; descontando esses dezoito do total de 37 contos presentes nas antologias acima arroladas, os outros dezenove se distribuem desigualmente entre as demais coletâneas.

Os contos que se repetem com maior frequência são $O$ gato preto e $A$ carta roubada, ambos com dez ocorrências entre as treze coletâneas - ausentes, portanto, apenas de três delas.

Segue-se uma relação dos contos em ordem decrescente pelo número de ocorrências nas várias Histórias extraordinárias. Entre parênteses constam as variantes dos títulos. ${ }^{7}$

- “O gato preto” (O gato negro); “A carta roubada” (A carta furtada): 10 ocorrências;

- “O escaravelho de ouro”: 9 ocorrências;

- "Berenice”; "William Wilson”; “A queda da casa de Usher”; “O barril de amontillado" (O barril de amontilhado); "O poço e o pêndulo”; "Manuscrito encontrado numa garrafa”; “Os crimes da rua Morgue” (Duplo assassínio na rua Morgue): 8 ocorrências;

- “O mistério de Marie Rogêt”; “Metzengerstein”: 5 ocorrências;

- “O sistema do dr. Alcatrão e do professor Pena” (O sistema do dr. Breu e do professor Pena); "Sombra — uma parábola” (Sombra); “A máscara da morte rubra” (A máscara da peste vermelha; A máscara da morte vermelha); “O homem da multidão” (O homem na multidão); “Nunca aposte sua cabeça com o diabo”; “A descida no interior do maelström” (Uma descida no maelström; Descida ao maelström): 4 ocorrências;

\footnotetext{
${ }^{7}$ Não incluí na contagem “O corvo (a gênese de um poema)”, "Método de composição” e $O$ corvo na tradução de Machado de Assis, publicados na edição da Ordibra/INL, 1972, por não se tratar de contos.
} 
- “Coração revelador” (O coração denunciador); "Ligéia”; “Pequena palestra com uma múmia” (Pequena discussão com uma múmia); “A aventura sem paralelo de um tal Hans Pfaall”; “Hop-frog”: 3 ocorrências;

- "O retrato ovalado" (O retrato oval); "O diabo no campanário”; “O caixão quadrangular” (A caixa quadrangular); "Silêncio” (Silêncio: uma fábula); “O duque de l’Omelette”; “O jogador de xadrez de Maelzel”; “A verdade sobre o caso do sr. Valdemar” (O caso do Valdemar); "Enterro prematuro” (O enterro prematuro): 2 ocorrências;

- “O poder da palavra”; “O demônio da perversidade”; "Rei peste”; “O encontro marcado”; “Deus (revelação magnética)”; “Eleonora”: 1 ocorrência.

IV.

Para além da digressão quantitativa, parece-me interessante analisar um pouco mais detidamente o uso do título Histórias extraordinárias em tão grande número de edições e seleções diferentes. Tanto mais porque, a partir de certa data, surgirá um equívoco grosseiro, que tem se perpetuado até hoje.

Vamos por partes.

1. Histoires extraordinaires de Charles Baudelaire e Histórias extraordinárias de José Paulo Paes ${ }^{8}$

Em 1856, foi publicado em Paris, por Michel Lévi Frères, Éditeurs, um volume de contos de Edgar Allan Poe selecionados e traduzidos por Charles Baudelaire, com o título de Histoires extraordinaires. A coletânea trazia treze contos, originalmente publicados em vários jornais e periódicos americanos entre 1832 e 1845.

Em 1958, foi publicado em São Paulo, pela editora Cultrix, um volume de contos de Edgar Allan Poe selecionados e traduzidos por José Paulo Paes, com o título de Histórias extraordinárias. A coletânea trazia dezoito contos. Desnecessário dizer que a fonte de inspiração para o título em português foi o nome dado à coletânea baudelaireana, aliás bastante feliz e sugestivo. Cabe notar, porém, que o conteúdo da coletânea é outro, totalmente independente da seleta feita por Baudelaire.

\section{A multiplicação das Histórias extraordinárias no Brasil}

\footnotetext{
${ }^{8}$ Ver seus respectivos conteúdos no Anexo.
} 
Um ano depois do lançamento da seleção traduzida por José Paulo Paes, a editora Civilização Brasileira publica outro volume de contos de Edgar Allan Poe, com seleção, prefácio, tradução e notas de Brenno Silveira. São onze histórias enfeixadas sob o título de Antologia de contos de Edgar Allan Poe.

Em 1970, a mesma editora publica essa seleta de Brenno Silveira, com pequenas alterações, ${ }^{9}$ mantendo os mesmos créditos pela organização e tradução da obra. O título da antologia, porém, é substituído por Histórias extraordinárias.

Assim, a partir de 1970 começam a conviver duas diferentes coletâneas de contos de Poe com o mesmo nome - e nenhuma delas, naturalmente, corresponde às Histoires extraordinaires baudelaireanas.

Ademais, na mesma década de 1970, multiplica-se o lançamento de antologias variadas usando o mesmo título de Histórias extraordinárias, como se pode ver na listagem apresentada no item IV. Aqui surge um detalhe que se mostrará relevante: em 1973, o volume da Civilização Brasileira de 1970 licenciado para o Círculo do Livro ganha mais quatro contos, ${ }^{10}$ e os créditos de tradução passam a se referir a "Brenno Silveira e outros”, silenciando sobre a responsabilidade pela seleção e organização da coletânea.

3. Histórias Extraordinárias, Histoires Extraordinaires $e$ Tales of the Grotesque and Arabesque

Em 1978, a editora Abril Cultural retoma o licenciamento das Histórias Extraordinárias da Civilização Brasileira em sua versão já um tanto alterada de 1973, e retira da coletânea um conto que vinha sendo publicado desde 1959: “O Duque de l’Omelette".

Neste momento ocorre um fato que veio a criar fundas raízes: o volume publicado pela Abril Cultural traz, à guisa de prefácio, um breve histórico da vida e obra do autor — infelizmente contendo erros grosseiros. Reproduzo: “Em 1838 [Poe] escreve A queda da casa de Usher e Contos do grotesco e do arabesco. [...] Em 1848, Contos do grotesco e do arabesco foi publicado na França como Histórias

\footnotetext{
${ }^{9}$ São acrescentados os contos "William Wilson” e "Nunca aposte sua cabeça com o diabo". No início do primeiro, um asterisco remete à nota "Tradução de Berenice Xavier”; no final do segundo, há um breve aviso: "A tradução deste conto nos foi gentilmente cedida pela Editora Globo, Porto Alegre" (sem os créditos a Oscar Mendes em colaboração com Milton Amado).

${ }^{10}$ São eles: "A aventura sem paralelo de um tal Hans Pfaall”, "O escaravelho de ouro", "Uma descida no Maelstrom” e o ensaio “O jogador de xadrez de Maelzel”, sem especificação de seus respectivos tradutores.
} 
extraordinárias, por Baudelaire”. Não seria exagero dizer que, nessas frases tão incisivas, somente um dado - e apenas implícito - é verdadeiro: Baudelaire morava na França. Mas a primeira consequência dessa afirmação despropositada se faz sentir no mesmo volume, que estampa na página da imprenta: "Título original: Tales of the Grotesque and Arabesque”.

Ora, basta comparar no Anexo quais são os 25 contos que compõem os dois volumes de Tales of the Grotesque and Arabesque (TGA) e os treze contos escolhidos por Baudelaire para Histoires extraordinaires (HEBaud). Outros erros grosseiros dizem respeito às datas:

a. Poe não escreveu TGA em 1838: a coletânea reúne contos escritos entre 1831 e 1839, ano em que foi publicada (mas com a data de 1840);

b. A coletânea de Baudelaire foi publicada em 1856, não em 1848;

c. Os contos da coletânea baudelaireana foram escritos entre 1832 e 1845 . Nada menos que nove deles nem tinham sido escritos à época em que Poe lançou suas TGA.

Como se sabe, o sistema de distribuição dos volumes publicados pela Abril Cultural se dava por bancas de jornais, além de venda domiciliar e por assinatura através do Círculo do Livro. São tiragens altíssimas, na faixa de 60 a 80 mil exemplares a cada edição, numa escala incomparável às tiragens normais para livrarias, na faixa de 2 a 3 mil exemplares cada, ou de 8 a 10 mil no caso das edições de bolso. Essa edição licenciada e publicada pela Abril Cultural em 1978, com o acréscimo do pequeno prefácio fantasioso, teve grande êxito, com várias reimpressões e sucessivas reedições, tanto pela própria Abril Cultural quanto pelo Círculo do Livro e, mais tarde, pela editora Nova Cultural, já em 2002-2003. Aqui estamos falando na casa de muitas centenas de milhares de exemplares de Histórias extraordinárias, apresentadas como tradução de Tales of the Grotesque and Arabesque.

Essa indevida remissão adquiriu tais foros de verdade que a própria Ediouro, que havia passado cerca de trinta anos atribuindo a responsabilidade pela organização de suas seletas de Poe a Clarice Lispector, a partir de 2005 adota a mesma referência, e suas Histórias extraordinárias — cujo conteúdo, aliás, pouco corresponde ao conteúdo licenciado pela Civilização Brasileira e muito menos ao das TGA — surgem também como tradução de Tales of the Grotesque and Arabesque. Afora o confrangimento que sentimos ao ler invectivas de estudiosos brasileiros a Baudelaire, censurando-lhe a falta 
de sensibilidade por traduzir o tão denso Tales of the Grotesque and Arabesque por algo tão plano quanto Histoires extraordinaires...

Assim, por iniciativa de um editor desatento em 1978 - decerto aflito, precisando descobrir qual seria o original daquela edição de 1973, traduzida por “Brenno Silveira e outros”, sem qualquer indicação de que se tratava de uma seleta local e, portanto, sem uma coletânea original que lhe correspondesse —, ficaram estabelecidas bizarras associações, que grassam fecundamente até a data de hoje: TGA = HEBaud; TGA = HEBras; HEBaud = HEBras; TGA = HEBaud $=$ HEBras. ${ }^{11}$

\section{Conclusões}

Esboço aqui algumas conclusões, de importância variável:

1. Se podemos afirmar com certa margem de segurança que a primeira coletânea de contos de Edgar Allan Poe foi publicada no Brasil por volta de 1903, ainda é incerta a autoria de sua tradução.

2. The Black Cat parece gozar de excepcional fortuna histórica entre nós, com grande vitalidade, sendo objeto de frequentes retraduções.

3. Histórias extraordinárias no Brasil é um título que se aplica a qualquer coletânea que se queira, com qualquer quantidade de contos que se pretenda. É um bom nome, com suas ressonâncias baudelaireanas e certa consagração difusa, e só. Justamente por não corresponder a Histoires Extraordinaires de Baudelaire e a nenhuma obra específica de Poe, é um título que não remete a nenhum conteúdo determinado. Por isso foi possível proliferarem tantas antologias diferentes com o mesmo nome.

4. Esta é a conclusão que me parece mais interessante do ponto de vista geral, e se divide em dois aspectos:

a. A coletânea de Histoires extraordinaires, tal como foi concebida por Charles Baudelaire, é inédita no Brasil;

b. E, principalmente, a coletânea de Tales of the Grotesque and Arabesque, tal como foi concebida por Edgar Allan Poe, jamais foi publicada entre nós.

\footnotetext{
${ }^{11}$ Ainda na linha das bizarrices, a editora Companhia das Letras, em suas Histórias extraordinárias, apesar de especificar na capa, na página de rosto e na ficha catalográfica que se trata de uma seleção de José Paulo Paes, menciona na mesma ficha CIP um insólito “Título original: Extraordinary tales”.
} 


\section{Anexo}

I.

Segue-se o conteúdo das diversas antologias com o nome de Histórias extraordinárias, por ordem cronológica da primeira edição.

1. Histórias extraordinárias, seleção e tradução de José Paulo Paes, Cultrix (1958) e Companhia das Letras (2008), com dezoito contos: “Coração revelador”; “O retrato ovalado"; "O sistema do dr. Alcatrão e do professor Pena”; "O gato preto”; “O diabo no campanário”; "Berenice”; “Sombra - uma parábola”; “William Wilson”; “O caixão quadrangular”; “A máscara da morte rubra”; “A queda da casa de Usher”; “A carta roubada"; "Ligéia”; "Pequena palestra com uma múmia”; "O barril de amontillado"; "O poço e o pêndulo"; “O escaravelho de ouro"; “O homem da multidão”.

2. Histórias extraordinárias, seleção e tradução de Brenno Silveira, Civilização Brasileira (1970), com treze contos: “A queda da casa de Usher”; "O barril de amontilhado"; “O gato preto"; "Berenice”; "Manuscrito encontrado numa garrafa”; “William Wilson”; “Os crimes da rua Morgue”; "O mistério de Marie Rogêt”; “A carta roubada”; "Metzengerstein”; 'Nunca aposte sua cabeça com o diabo”; “O poço e o pêndulo”; “A aventura sem paralelo de um tal Hans Pfaall”.

3. Histórias extraordinárias, pretensa tradução de João Teixeira de Paula, com dezesseis contos: "O poço e o pêndulo"; “O escaravelho de ouro"; "O homem na multidão”; “Berenice”; “Hop Frog”; "William Wilson”; "Silêncio”; “Sombra”; “A carta roubada”; “O gato preto”; “O poder da palavra”; "Pequena discussão com uma múmia”; “O demônio da perversidade”; “O sistema do doutor Breu e do professor Pena”; "Rei peste”; "Duplo assassínio na rua Morgue”. Traz também “O corvo (a gênese de um poema)”, "Método de composição” e a tradução de O corvo por Machado de Assis.

4. Histórias extraordinárias, tradução de Brenno Silveira e outros, Civilização Brasileira (1973) em licença para o Círculo do Livro, com dezessete contos: “A queda da casa de Usher”; "Berenice”; 'Os crimes da rua Morgue”; “O escaravelho de ouro”; “O gato negro”; “O barril de amontillado”; “Manuscrito encontrado numa garrafa”; “William Wilson”; “O mistério de Marie Rogêt”; “A carta roubada”; “Metzengerstein”; 
“O poço e o pêndulo”; “Nunca aposte sua cabeça com o diabo”; "Uma descida no maelström”; 'O duque de l’Omelette”; “O jogador de xadrez de Maelzel”; “A aventura sem paralelo de um tal Hans Pfaall”.

5. Histórias extraordinárias de Allan Poe, seleção e tradução de Clarice Lispector, Ediouro (seleta de c. 1975, com esse título desde c. 1985), e Histórias extraordinárias, tradução de Clarice Lispector, Ediouro (2005), com dezoito contos: “O gato preto"; “A máscara da morte rubra”; “O caso do Valdemar”; "Manuscrito encontrado numa garrafa”; "Enterro prematuro”; “Os crimes da rua Morgue”; “A queda da casa dehttp://4.bp.blogspot.com/_zVPImTviU9s/SjO24GSbmI/AAAAAAAACbA/DZGuJT31ZPM/s1600-h/818024.jpg Usher”; “Os dentes de Berenice”; “Nunca aposte sua cabeça com o diabo”; “O duque de l’Omelette”; “William Wilson”; “O retrato oval”; “O coração denunciador”; “O diabo no campanário”; "O barril de amontillado”; “Metzengerstein”; “Ligéia”; “Deus (revelação magnética)”.

6. Histórias extraordinárias, tradução de Brenno Silveira e outros, Edibolso (3a. ed., 1975), com onze contos: “A máscara da peste vermelha”; “O enterro prematuro”; “A caixa quadrangular”; “O homem na multidão”; "William Wilson”; “O poço e o pêndulo”; “A queda da casa de Usher”; “O barril de amontillado”; “O gato preto”; “O coração revelador”; "Berenice”.

7. Histórias extraordinárias, tradução de Brenno Silveira e outros, Civilização Brasileira (1978) em licença para Abril Cultural, Círculo do Livro, Nova Cultural, com dezesseis contos: “A queda da casa de Usher”; “O barril de amontilhado”; “O gato preto"; "Berenice”; “Manuscrito encontrado numa garrafa”; "William Wilson”; “Os crimes da rua Morgue”; “O mistério de Marie Rogêt”; “A carta roubada”; "Metzengerstein”; “Nunca aposte sua cabeça com o diabo”; “O poço e o pêndulo”; “A aventura sem paralelo de um tal Hans Pfaall”; “O escaravelho de ouro”; "Uma descida no maelstrom”; “O jogador de xadrez de Maelzel”.

8. Histórias extraordinárias, seleção de Carmen Vera Cirne Lima, tradução de Oscar Mendes e Milton Amado, Globo (1987) [não disponho do conteúdo desta seleta].

9. Histórias extraordinárias, pretensa tradução de Pietro Nassetti, Martin Claret 
(1999), com sete contos: “O gato preto”; "Manuscrito encontrado em uma garrafa”; “Os crimes da rua Morgue”; “A carta roubada”; “O poço e o pêndulo”; “O escaravelho de ouro”; “A queda da casa de Usher”.

10. Histórias extraordinárias, tradução de Cláudia Ortiz, Escala/Larousse (2005), com sete contos: “A carta roubada”; “A queda da casa de Usher”; “O gato preto”; “O barril de amontillado”; “A máscara da morte vermelha”; "Hop-frog”; “O escaravelho de ouro".

http://1.bp.blogspot.com/_zVPImTviU9s/SjPK-

fUOUNI/AAAAAAAACcQ/xt00tg1U0wY/s1600-

h/poe,+ed.+am\%C3\%A9rica+do+sul.jpg11. Histórias extraordinárias, tradução portuguesa de Luísa Feijó e Teixeira de Aguilar, em edição brasileira pela América do Sul (1988), com seis contos: “Os crimes da rua Morgue”; “O escaravelho de ouro”; “O gato negro"; "O barril de amontillado"; "Manuscrito encontrado numa garrafa"; "Eleonora”.

Essas onze coletâneas diferentes de Histórias extraordinárias incluem O gato preto. Há outras três com o mesmo título, mas sem o referido conto.

12. Histórias extraordinárias, tradução anônima, http://2.bp.blogspot.com/_zVPImTviU9s/SjPYqUw7pFI/AAAAAAAACcY/RoQFZ7vq qEM/s1600-h/poe,+otto+pierre+he.jpgOtto Pierre (1979), com oito contos: “Os crimes da rua Morgue”; “O mistério de Marie Roget”; “O escaravelho de ouro”; “O sistema do dr. Alcatrão e do prof. Pena”; “A verdade sobre o caso do sr. Valdemar”; "Descida ao maelstrom”; “A carta roubada”; “Metzengerstein”.

13.http://4.bp.blogspot.com/_zVPImTviU9s/SjO4dsG42DI/AAAAAAAACbg/6 BA6Syy-Igw/s1600-h/poe+clube+do+livro+88+sem+gato+preto+pequeno.jpg Histórias extraordinárias, tradução de José Maria Machado, Clube do Livro (1988), com dez contos: "O escaravelho de ouro”; “O homem na multidão”; "Hop Frog”; "William Wilson”; "Silêncio (uma fábula)”; "Sombra (uma parábola)”; "Berenice”; "Pequena discussão com uma múmia”; “A carta roubada”; “O sistema do dr. Breu e do professor Pena”. 
14. Histórias extraordinárias, tradução de Pedro Ramires, Cedibra (1972), com oito contos: “O encontro marcado”; “Ligéia”; “O poço e o pêndulo”; “Manuscrito encontrado numa garrafa"; "Descida ao interior do maelström”; “O mistério de Marie Rogêt”; “A carta furtada”; “Sombra — uma parábola”.

II.

Histoires extraordinaires é uma coletânea de treze contos de Edgar Allan Poe, selecionados e traduzidos por Charles Baudelaire, publicada em 1856. Traz os seguintes contos (entre parênteses, a data da publicação original nos Estados Unidos):

“Double Assassinat dans la rue Morgue” (1841); “La Lettre volée” (1844); “Le Scarabée d’or” (1843); “Le Canard au ballon” (1844); “Aventure sans pareille d'un certain Hans Pfaall” (1835); “Manuscrit trouvé dans une bouteille” (1833); “Une Descente dans le Maelstrom” (1841); “La Vérité sur le cas de M. Valdemar” (1845); “Révélation magnétique” (1844); “Souvenirs de M. Auguste Bedloe” (1844); “Morella” (1835); “Ligeia” (1838); “Metzengerstein” (1832).

III.

Tales of the Grotesque and Arabesque é uma coletânea de 25 contos que Poe selecionou e lançou em novembro/dezembro de 1839, com data de 1840, em dois volumes. Ela reúne contos escritos entre 1831 e 1839, que podem ser consultados no site da The Edgar Allan Poe Society of Baltimore.

Volume I: “Morella” (1835); “Lionizing” (1835); “William Wilson” (1839); “The Man That Was Used Up” (1839); “The Fall of the House of Usher” (1839); “The Duc de l'Omelette” (1831); “MS. Found in a Bottle” (1833); “Bon-Bon” [The Bargain Lost] (1831); “Shadow — A Parable” (1835); “The Devil in the Belfry” (1839); “Ligeia” (1838); “King Pest” (1835); “The Signora Zenobia” (1838); “The Scythe of Time” (1838).

Volume II: “Epimanes” (1833); “Siope” [Silence — A Fable] (1832); “The Unparalleled Adventure of One Hans Pfaal” (1835); “A Tale of Jerusalem” (1832); “Von Jung” [Mystification] (1837); “Loss of Breath” [A Decided Loss] (1831); "Metzengerstein” (1831); "Berenice” (1834); “Why the Little Frenchman Wears His 
Hand in a Sling” (1837); “The Visionary’ [The Assignation] (1832); “The Conversation of Eiros and Charmion” (1839), e um apêndice ao conto "Hans Pfaal”. 


\section{Fontes de consulta}

ABRAMO, Cláudio W. A espada no livro. Publicação eletrônica disponível em www.scribd.com/doc/18047587/analise-corvo, 1999.

ARAÚJO, Ricardo. Edgar Allan Poe: Um homem em sua sombra. São Paulo: Ateliê Editorial, 2002.

BIBLIOTECA NACIONAL DE PORTUGAL. Catálogos online, www.bnportugal.pt.

DAGHLIAN, Carlos. A recepção de Poe na literatura brasileira. Fragmentos 17, p. 714. Florianópolis: UFSC, jul-dez 1999. Disponível em http://www.periodicos.ufsc.br/index.php/fragmentos/article/view/6370/5927.

. “Bibliografia”. Fragmentos 17, p. 95-111. Florianópolis: UFSC, jul-dez 1999. Disponível

em www.periodicos.ufsc.br/index.php/fragmentos/article/view/6371/5935.

ESTANTE VIRTUAL, Central de sebos nacionais, www.estantevirtual.com.br.

FUNDAÇÃO BIBLIOTECA NACIONAL. Catálogos online, www.bn.br.

HALLEWELL, Laurence. O livro no Brasil. Tradução de Maria da Penha Villalobos e Lólio Lourenço de Oliveira. São Paulo: TAQ/ EDUSP, 1985.

POE, Edgar. Novellas extraordinarias. Tradução anônima. 344p. Rio de Janeiro/Paris: H. Garnier, Livreiro-Editor, s/d, c. 1903.

. Novelas extraordinárias. Tradução portuguesa, revista por Faria e Sousa. 224p. São Paulo: O Livro de Bolso, 1941.

Novelas extraordinárias. Tradução de Faria e Souza. 189p. São Paulo: Cruzeiro do Sul, 1943.

Novelas extraordinárias. Tradução anônima. 208p. São Paulo: Clube do Livro, 1945.

Histórias extraordinárias. 240p. São Paulo/ Brasília: Ordibra, INL, 1972.

. O escaravelho de ouro e outros. Tradução de Mécia Mousinho de Albuquerque. Biblioteca universal antiga e moderna, vol. 37, 124p. Lisboa: Companhia Nacional, 1889.

. O rei peste e outros. Tradução de Mécia Mousinho de Albuquerque. Biblioteca universal antiga e moderna, vol. 61, 126p. Lisboa: Companhia Nacional, 1890.

SOUSA, Maria Leonor M. de. Poe in Portugal. In: VINES, Lois Davis (Org.). Poe Abroad. Iowa: Univ. Iowa Press, 1999, p. 115-20.

THE EDGAR ALLAN POE SOCIETY OF BALTIMORE, www.eapoe.org.

Agradeço a Joana Canêdo, Carlos Daghlian e Saulo von Randow Jr. por várias indicações úteis. Para outros dados relacionados, ver http://naogostodeplagio.blogspot.com, no arquivo "Pesquisa Poe no Brasil”. 